\section{Displasia de la cadera}

\author{
Hip dysplasia
}

\section{DEFINICIÓN}

Antiguamente conocida como luxación congénita de la cadera, actualmente se prefiere el término de displasia del desarrollo de la cadera por su carácter evolutivo y de aparición posnatal.

\section{GENERALIDADES}

La mayoría de los investigadores piensa en una combinación de factores en los que interviene, principalmente, un componente hereditario con penetrancia limitada. Esa sería la causa principal que, asociada con factores mecánicos como la posición en el útero, la cantidad de líquido amniótico, la forma de envolver a los recién nacidos y problemas musculares como debilidad del músculo glúteo medio, ya sea real o debida a la fuerza de los aductores y el músculo psoas.

Por lo anterior, siempre que exista un antecedente en la familia debe insistirse en la búsqueda de esta afección; también cuando el paciente tenga tortícolis o deformidades en los pies: equino varo o talo; haciendo énfasis en que la exploración debe repetirse cada mes los primeros seis meses ya que, por el carácter evolutivo del padecimiento, puede pasar inadvertido inicialmente y después tornarse evidente.

\section{DATOS CLÍNICOS}

El dato clave en esta edad es la limitación de la abducción de una o ambas caderas ya que normalmente, con las rodillas flexionadas, un recién nacido tranquilo (sin Ilanto) permite que ambas rodillas toquen la superficie de la mesa de exploración simultáneamente (Figuras 1 y 2).
Agustín Isunza-Ramírez ${ }^{1}$ Oscar Daniel Isunza-Alonso ${ }^{2}$

${ }^{1}$ Director Médico del Hospital Germán Díaz Lombardo.

${ }^{2}$ Médico adscrito al Departamento de Ortopedia Pediátrica, Instituto Nacional de Pediatría, México.

Recibido: 3 de febrero del 2015

Aceptado: 31 de marzo del 2015

Correspondencia: Dr. Agustín Isunza Ramírez Hospital Germán Díaz Lombardo Donagusmx@yahoo.com.mx

Este artículo debe citarse como Isunza-Ramírez A, Isunza-Alonso OD. Displasia de la cadera. Acta Pediatr Mex 2015;36:205-207. 


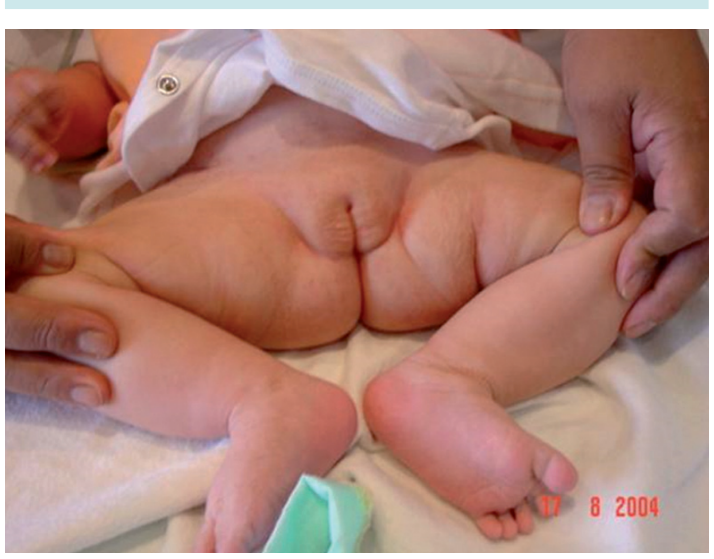

Figura 1. Caderas normales.

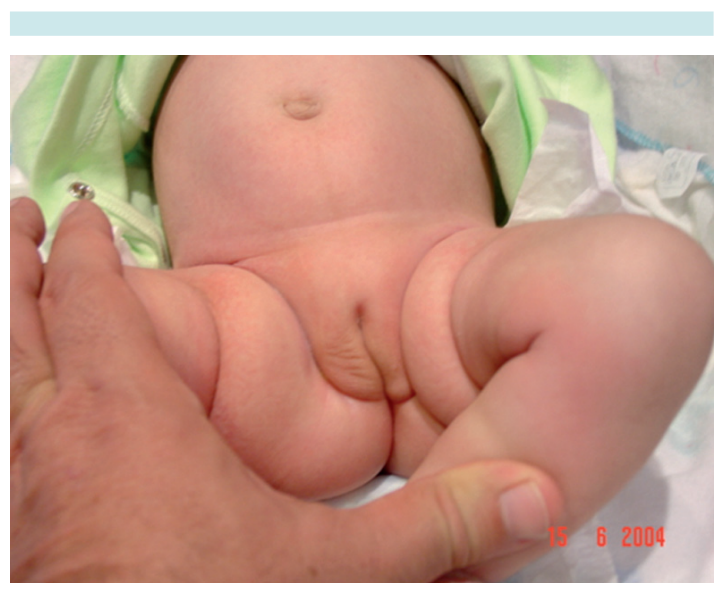

Figura 2. Limitación de la abducción de cadera izquierda.

Cuando no se logra la apertura de las caderas, se determina que existe limitación de la abducción, dato clave para el diagnóstico de displasia de la cadera en desarrollo.

Otro dato importante es la asimetría de los pliegues; sin embargo, hay pliegues "mentirosos": los de la mitad del muslo debidos a la acumulación de grasa. Los pliegues que sí son patológicos son los de los labios mayores, los de los glúteos y los poplíteos (Figura 3).

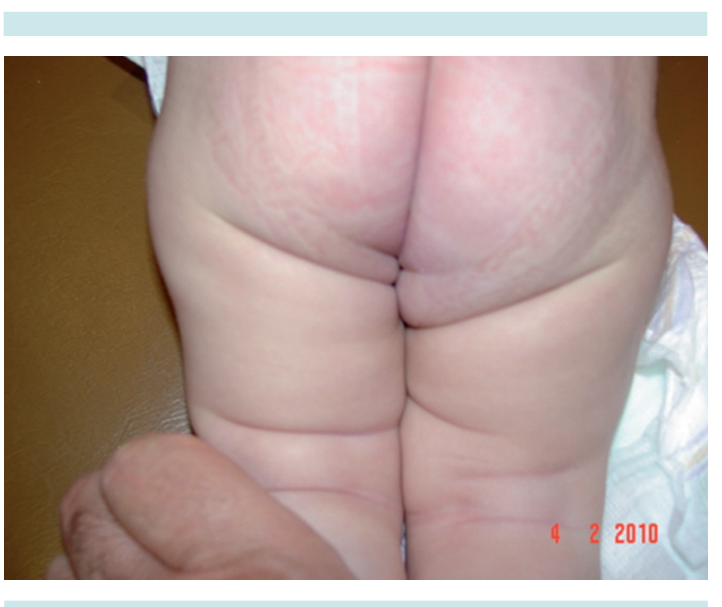

Figura 3. Asimetría de pliegues.

\section{Asimetría en pliegues}

En el recién nacido existen pruebas de inestabilidad conocidas como pruebas de Barlow y Ortolani, que se acompañan de sonidos característicos conocidos como "clic" de entrada y de salida; que deberán practicar sólo un número de veces indispensable para hacer el diagnóstico ya que si se realizan con mucha frecuencia aumentan el peligro de dañar el cartílago de crecimiento y el articular.

Maniobra de Barlow. Con el paciente en decúbito supino se toma con la mano exploradora la rodilla contraria del paciente y con la otra mano se fija la pelvis, se realiza aducción del muslo y con ligera presión a nivel de la rodilla se luxa la cadera; en este momento se escuchará "clic" que es la cadera que se luxa, lo cual significa que es una cadera inestable.

Maniobra de Ortolani. Es similar a la anterior, pero con los dedos índice y medio de la mano exploradora apoyados en el trocánter mayor, se hace presión al mismo tiempo que se realiza abducción y, si estuviera luxada, se escuchará un chasquido de entrada de la cadera. 
Ambas maniobras sólo son útiles en los primeros 40 días de edad; posteriormente, la evolución del padecimiento o el aumento de la consistencia de los tejidos periarticulares hace difícil realizar las maniobras.

La asimetría en la longitud de las extremidades es útil cuando la alteración es unilateral. En extensión de las extremidades inferiores se observará un acortamiento del lado de la cadera displásica. Así mismo, con las rodillas flexionadas y los pies apoyados en un mismo plano, de preferencia sólido, se observa la diferencia de alturas de una de las rodillas (Allis o Galeazzi positivos) (Figuras 4 y 5).

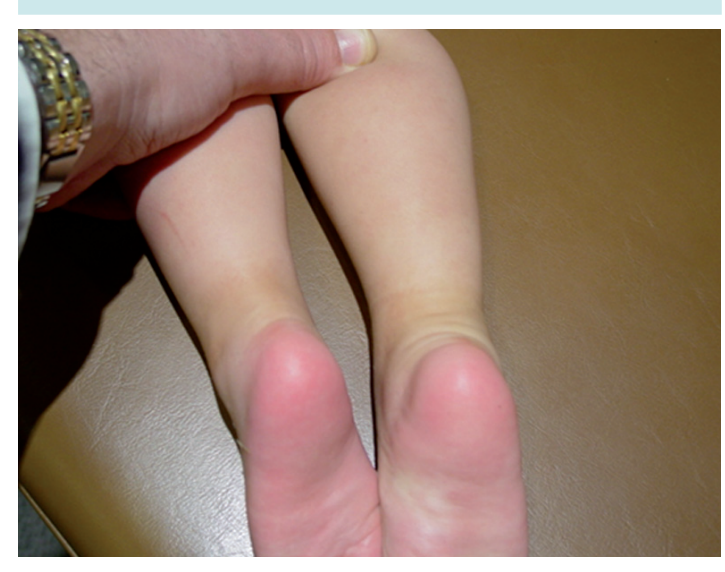

Figura 4. Asimetría de pliegues.
Las alteraciones en la marcha y la maniobra de pistón son datos demasiado tardíos de la displasia de cadera, por lo que no se describirán en este artículo.

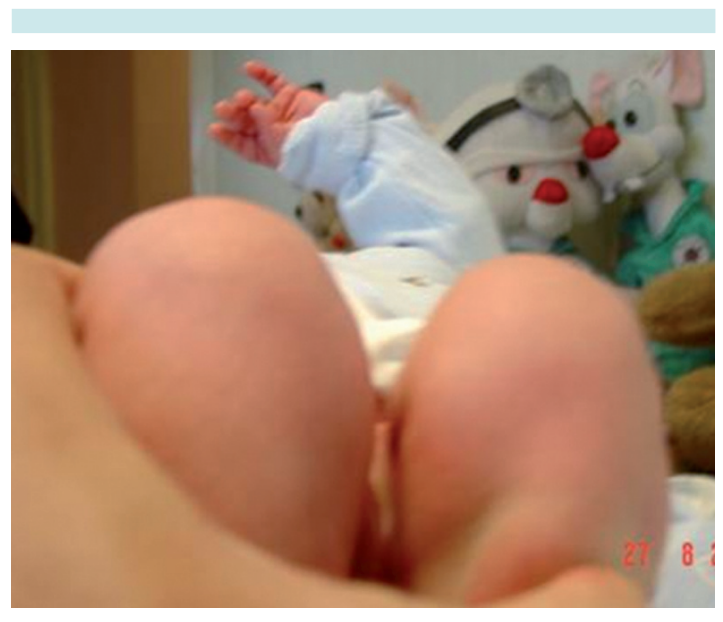

Figura 5. Allis o Galeazzi positivo. 